1. M.B.B.S, M.Phil. Department of Pharmacology and Therapeutics, Nawaz Sharif Medical College University of Gujrat.

2. MBBS, M.Phil., Ph.D.

HOD of Department of

Pharmacology and Therapeutics. Army Medical College, NUST. Rawalpnidi.

3. M.B.B.S, MSPH Department of Community Medicine and Public Health, Nawaz Sharif Medical College, University of Gujrat.

Correspondence Address:

Dr. Ammara Khan

Department of Pharmacology and Therapeutics,

Nawaz Sharif Medical College. University of Gujrat, Gujrat.

drammara19@gmail.com

Article received on: 01/01/2015

Accepted for publication: $18 / 08 / 2015$

Received after proof reading: 12/10/2015

\section{HEPATOTOXICITY; PREVENTIVE AND THERAPEUTIC ROLE OF DEXAMETHASONE IN LPS/ENDOTOXIN INDUCED.}

\section{Dr. Ammara Khan', Prof. Brig. Akbar Waheed ${ }^{2}$, Dr. Zahid Azam Chaudry ${ }^{3}$}

ABSTRACT... Background of Study: Sepsis is characterized by overwhelming surge of cytokines and oxidative stress to one of many factors, gram negative bacteria being one of it. Mortality remains very high in septic patients despite the advanced treatments rendered in intensive care units due to multiple organ damage including hepatotoxicity. Study Design: Randomized controlled laboratory trial. Period: 04 months from March 2014-June 2014. Setting: Department of Pharmacology and Therapeutics, Army Medical College, NUST, Rawalpindi. Aim of the Study: The present study was undertaken to learn dexamethasone's competence in prevention and treatment of LPS/ endotoxin induced hepatotoxicity in mice. Material and Methods: Endotoxin induced hepatotoxicity was reproduced via LPS of serotype E.Coli O111:B4 administrationintraperitoneally at a dose of $10 \mathrm{mg} / \mathrm{kg}$ and all mice were sacrificed 17 hours latters. Dexamethasone (3mg/kg of b.w. i.p) was given 30 minutes before LPS in separate set of animals to determine its preventive role. Whereas therapeutic efficacy was adjudged by giving dexamethasone 2 hour after LPS administration. Hepatotoxicity was determined by estimation of serum ALT and AST and histopathological analysis of liver sections. Results: LPS administration was associated by statistically elevated serum ALT and AST and marked hepatic inflammation. Dexamethasone was efficacious in a version of LPS induced hepatic dystrophy both when given as pre and post-treatment. Serum ALT and AST were statistically lower when compared to LPS group. Also hepatic inflammation was statistically lessened by dexamethasone. Conclusion: Low dose dexamethasone has beneficial role in reduction of LPS/endotoxin induced hepatic injury in experimental model of sepsis.

Key words: LPS, Endotoxin, Hepatotoxicity, Dexamethasone

Article Citation: Khan A, Waheed A, Chaudry ZA. Hepatotoxicity; preventive and therapeutic role of dexamethasone in LPS/ endotoxin induced. Professional Med J 2015;22(10):1309-1315. DOI: 10.17957/TPMJ/15.2749

\section{INTRODUCTION}

Although immune response salvages human life against deadly infections due to pathogens, but a hyper and dys-regulated immune response to infection leads to sepsis. Sepsis still represents a major dilemma calling a devastating death toll not only in developing countries like Pakistan but also in USA. It contributes $6 \%$ of all deaths in USA $^{1}$ and mortality rate is as high as $70 \%$ due sepsis induced organ failure including hepatotoxicity. ${ }^{2}$ The ensuing end of life in sepsis is a result of multiple organ failure, beginning at one and then involving other organs including hepatotoxicity. Due to liver's implication in almost all biological processes including detoxification of bacterial products like LPS absorbed through portal circulation, its integrity is essential for patients of trauma, surgery and infection. Gram negative bacteria are primary offenders in $50 \%$ of septic cases ${ }^{3}$ activating host innate immune response through outer cell wall molecule called endotoxin / Lipopolysaccharide. Lipopolysaccharide binding protein (LBP) synthesized in liver, marshals LPS to CD14 membranous receptor and Toll like Receptor type 4 (TLR4) on Kupffers cells. ${ }^{4}$ This brings about activation and phosphorylation of series of kinases, aftereffect of which is release of cytotoxic pro-inflammatory mediators like andTNF-alpha, IL-1, IL6 , IL-8, reactive oxygen species and induction of inducible nitric oxide synthase (iNOS). ${ }^{5}$ All of this conclude in sepsis, shock and endotoxin induced hepatocellular necrosis and apoptosis.

The role of dexamethasone in sepsis is still contentious but experts favoring its use in sepsis induced hepatotoxicity are of the view that majority 
of septic patients have accompanying transient adrenal failure. ${ }^{6}$ This proves lethal due aggravation of hemodynamic instability and accentuation of inflammation in these critically ill patients. Dexamethasone is long acting potent anti-inflammatory glucocorticoid. After binding to its dormant cytoplasmic glucocorticoid receptor, dexamethasone invokes disjunction of multimeric protein complex and trans-location to nucleus wherein it induces production of anti-inflammatory proteins like annexin-1 and inhibitors of nuclear factor kappa B (NF-kb) and also inhibits inflammatory gene synthesis. ${ }^{7}$ Dexamethasone is also said to interact with membranous glucocorticoid receptor causing reduced phosphorylation of T-cell associated kinases. ${ }^{8}$

Previous studies have documented beneficial role of low dose steroids that is $3 \mathrm{mg} / \mathrm{kg}$ of body weight of dexamethasone or equivalent, in various animal models if sepsis through declined production of inflammatory mediators ${ }^{9,10}$, improved hemodynamic status of organs and reduction of organ failure in sepsis. ${ }^{11,12}$ However many clinical trials have failed to show positive influence of steroids on morbidity and mortality rates in sepsis. ${ }^{13}$ Further these experts also document increased episodes of adverse effects when steroids are administered to septic patients. ${ }^{14}$

Above mentioned controversial observations regarding steroid use in sepsis induced organ failure prompted us to access the role of dexamethasone in prevention and treatment of endotoxin/ LPS induced hepatotoxicity in mice.

\section{MATERIAL AND METHODS}

\section{Study place}

Department of Pharmacology and Therapeutics, Army Medical College, NUST, Rawalpindi.

\section{Study duration}

04 months from March 2014-June 2014.

\section{Study design}

It was a Randomized controlled laboratory trial. Majority of extraneous factors like age, diet, gen- der, environment, and housing condition were accounted for.

\section{Sampling technique and sample size}

24 to 28 animals were initially selected through non-probability convenience method and latter randomly divided into four groups. At least six animals were present in each group.

\section{Animals used}

Adult male and female white albino mice weighing 40-50 grams were utilized in the study. They were housed in wire topped cages under controlled temperature $\left(20-24^{\circ} \mathrm{C}\right)$ and humidity $(40-50 \%)$. A12 hour light and 12 hour dark cycle was maintained throughout the study. Commercial rodent pellet diet and tap water was provide ad libitum. All animals were initially allowed to acclimatizeto new environment for at least 8 days prior to any experimentation.

\section{Chemical agents used}

Lipopolysaccharides (LPS) of serotype E.Coli O111:B4 was purchased from Sigma Aldrich chemicals, USA. It was dissolved in sterile phosphate buffered saline (PBS) in falcon tube. Dexamethasone was bought from Amros Pharmaceuticals, Pakistan.

\section{Experimental design}

Animals were divided into four groups as follows.

\section{Group 1 (Control Group)}

Six mice in this group received intraperitoneal injection of normal saline. It served as control group.

\section{Group 2 (LPS group)}

Animals $(n=6)$ of this group received intraperitoneally LPS at a dose of $10 \mathrm{mg} / \mathrm{kg}^{9}$

\section{Group 3 (dexamethasone pre-treatment Group)}

This group also had six white albino mice. These mice were given $3 \mathrm{mg} / \mathrm{kg}$ of body weight of dexamethasone intraperitoneally 30 minutes before LPS administration. 
Group 4 (dexamethasone post-treatment group)

Six mice in this group were administered $10 \mathrm{mg} /$ kg LPS intraperitoneally followed 2 hours later by $3 \mathrm{mg} / \mathrm{kg}$ of dexamethasone intraperitoneal injection. This time interval of two hours was chosen on basis of previous studies showing that TNF-alpha levels peaks one hour after LPS injection. ${ }^{15}$

\section{Blood and Tissue collection}

Initial blood sampling of all animals at 0 hour (start of experiment) was done from tail vein and blood was collected in eppendorf tube. At 17 hours, terminal blood sample was taken by cardiac puncture and $0.8-1.5 \mathrm{ml}$ of blood was collected. Mice were killed and liver was quickly removed, washed with PBS and stored in labeled container containing $10 \%$ formaldehyde for latter histopathological analysis.

\section{Markers of Liver Damage}

Assessment of Serum ALT and AST

Blood collected at 0 hour (start of experiment) and 17 hour (end of experiment) was centrifuged for 10 minutes at $4000 \mathrm{rpm}$ to separate serum. Serum ALT and AST levels were estimated of all initial and terminal blood samples by method recommended by International Federation of Clinical Chemistry (IFCC) using Merck kits on auto analyzer. Results were expressed as IU/L.

\section{Histopathological studies}

Livers sections were processed through LEICA TP1020 automatic tissue processor and stained with Hemotoxylin and eosin for light microscopy at 20X and 40X magnification. Periportal or periseptal hepatitis, confluent necrosis, focal lytic necrosis, apoptosis and portal inflammation were looked for and graded according to Modified Histological Activity Index Grading (Knodells method). ${ }^{16}$ Fibrosis was not included as time duration of study was short. ${ }^{17}$

\section{STATISTICAL ANALYSIS}

Results were expressed as Means \pm Standard Error of Means. The between group observations variation was measured by One Way Analysis of Variance (ANOVA) followed by Post Hoc Tukey test. Histopathological results were assessed through Chi Square test. A p value of $\leq 0.05$ was considered significant. All data analysis was carried out using SPSS version 20.

\section{RESULTS}

Hepatotoxic model was standardized in our laboratory utilizing different doses and time interval before animal sacrifice. A dose of $10 \mathrm{mg} / \mathrm{kg}$ of LPS followed by sacrifice after 16-17 hours, produced marked hepatotoxicity as evident by raised serum ALT and AST levels and marked histopathological alterations on liver slides.

\section{EFFECT ON SERUM ALT AND AST}

Normal saline administration in animals of Group 1 showed no effects on makers of liver damage assessment. Serum ALT and AST at 17 hours were somewhat similar to those at 0 hour, a statistically insignificant finding with $p$ value of $\geq 0.05$ for both levels (Figure-1 and figure-2).

LPS administration in mice of Group 2 caused Liver function test escalation. Serum ALT levels raised statistically significantly $(p \leq 0.05)$ from mean $106.00 \mathrm{IU} / \mathrm{L}$ (at 0 hour) to $345.17 \mathrm{IU} / \mathrm{L}$ at 17 hours. Serum AST showed similar trends with its values raising convincingly $(\leq 0.05)$ from 90.50 $\mathrm{IU} / \mathrm{L}$ to $343.17 \mathrm{IU} / \mathrm{L}$ at 17 hours. Serum ALT and AST levels of animals of Group 2(LPS Group) at 17 hours when compared to those of group 1 (normal/control group) were compelling elevated statistically $(p \leq 0.05)$ (Table-l). Dexamethasone pre-treatment prevented the hepatotoxic manifestations of LPS in animals of Group 3 (figure-2, Table-I). Serum ALT and AST at 17 hours were significantly $(p \leq 0.05)$ reduced when dexamethasone was given 30 prior to LPS administration in these animals. Animals of group 4 that received dexamethasone after LPS administration also had statistically eloquently $(p \leq 0.05)$ lessened serum ALT and AST rise at 17 hours as compared to Group 2 (LPS group)(Figure-1 \& 2, table-I). 


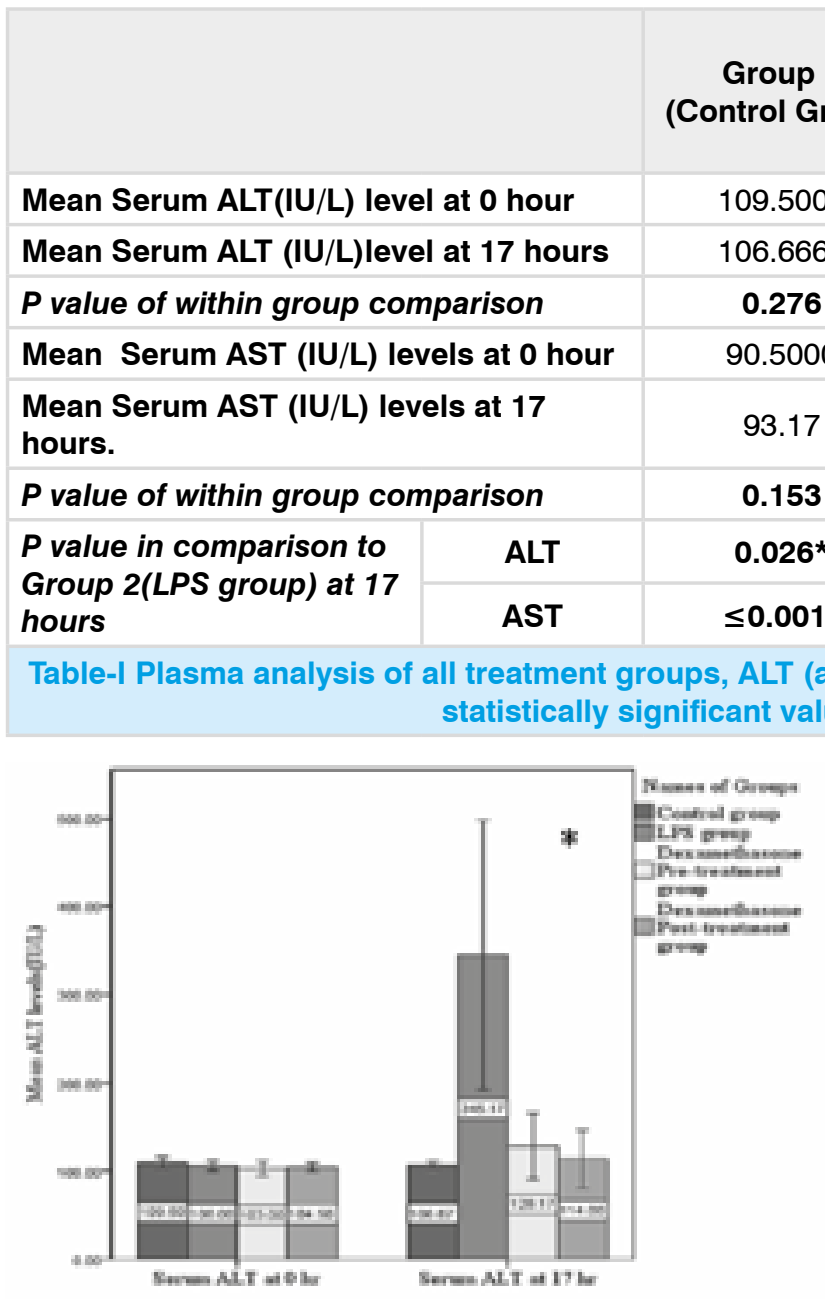

Figure-1. Mean Serum ALT (IU/L) Levels at 0 hour (Start of Experiment) and at 17 hour (End of Experiment). *Significantly ( $p \leq 0.05)$ Higher Than Control Group (Group 1); \#Significantly $(p \leq 0.05)$ Lower Than LPS Group (Group 2).

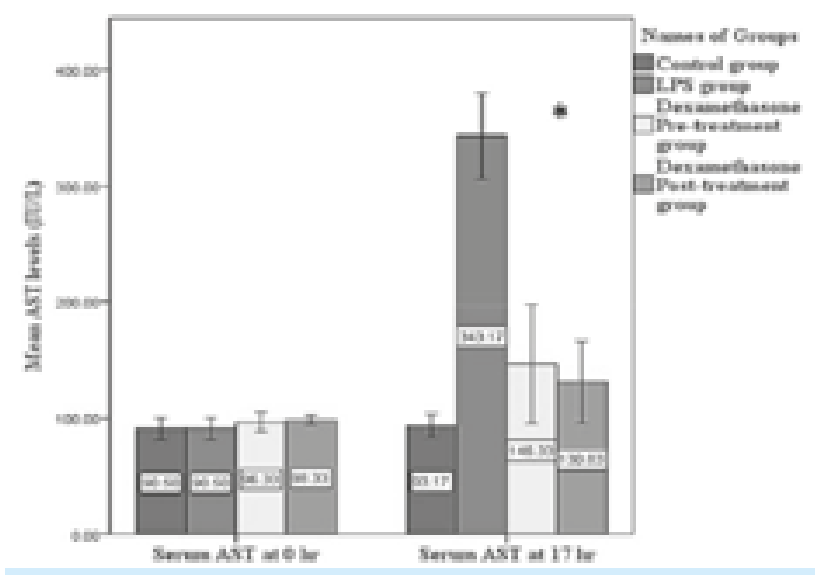

Figure-2. Mean Serum AST (IU/L) Levels At 0 hour (Start of Experiment) and at 17 hour (End of Experiment). *Significantly $(p \leq 0.05)$ Higher Than Control Group (Group 1); \#Significantly ( $\leq \leq 0.05)$ Lower Than LPS Group (Group 2).

Group3 Group4

(Dexamethasone (Dexamethasone

Pre-Treatment Post-Treatment

Group) Group)

\begin{tabular}{l|l}
103.00 & 104.50
\end{tabular}

\begin{tabular}{l|l}
128.17 & 114.00
\end{tabular}

\begin{tabular}{|l|l|l|}
\hline 0.024 * & 0.181 & 0.554 \\
\hline
\end{tabular}

\begin{tabular}{|l|l|l|}
\hline 90.50 & 96.33 & 98.33 \\
\hline
\end{tabular}

\begin{tabular}{|l|l|l|}
\hline 343.17 & 146.33 & 130.83 \\
\hline
\end{tabular}

\begin{tabular}{|l|l|l|}
\hline $\mathbf{0} 001^{*}$ & 0.115 & 0.118
\end{tabular}

\begin{tabular}{|c|c|c|}
\hline ND & $0.02 *$ & $0.014^{\star}$ \\
\hline ND & $\leq 0.001^{*}$ & $\leq 0.001^{*}$
\end{tabular}




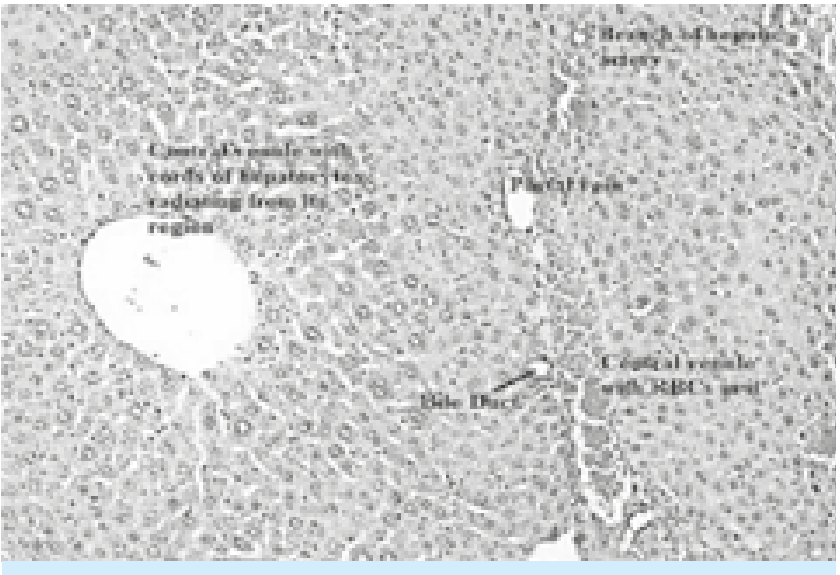

Figure-3. Group 1- Normal histology of Mouse Liver at $20 \mathrm{X}$ magnification.

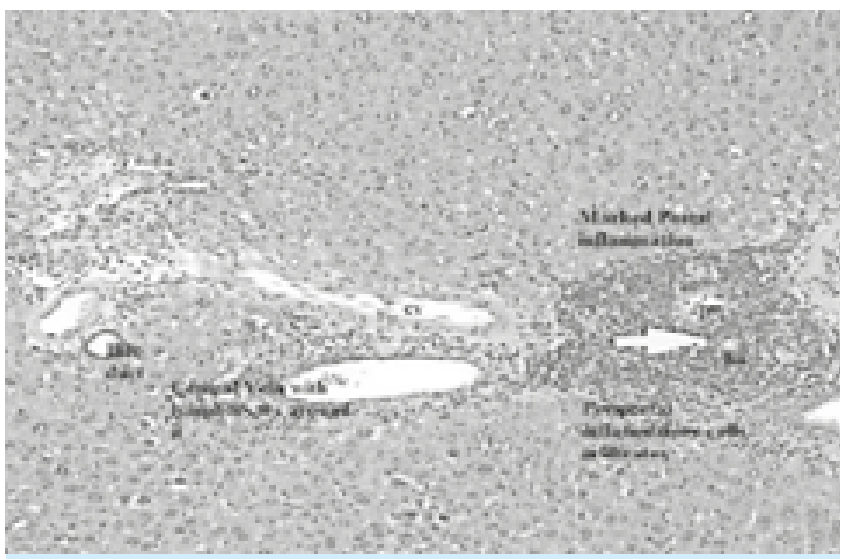

Figure-4. Group 2- Liver sections showing marked inflammation in response to LPS in Group 2. PV -portal vein, CV central venule. ha-hepatic arteriole

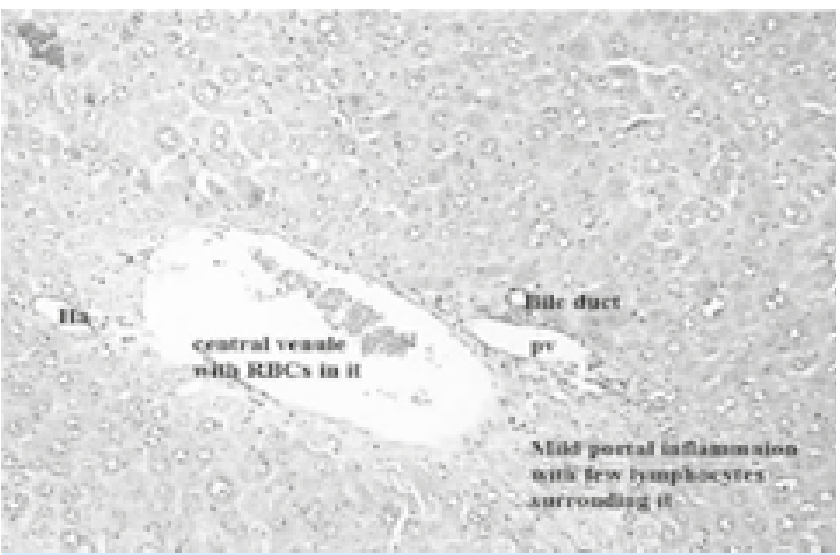

Figure-5. Group 3-dexamethasone pretreatment contracted inflammation in response to LPS. PV -portal vein, HA-hepatic arteriole.

\section{DISCUSSION}

A generalized body reaction to infection, sepsis involves interaction of various biological system and cell types with resultant dys-regulated inflam-

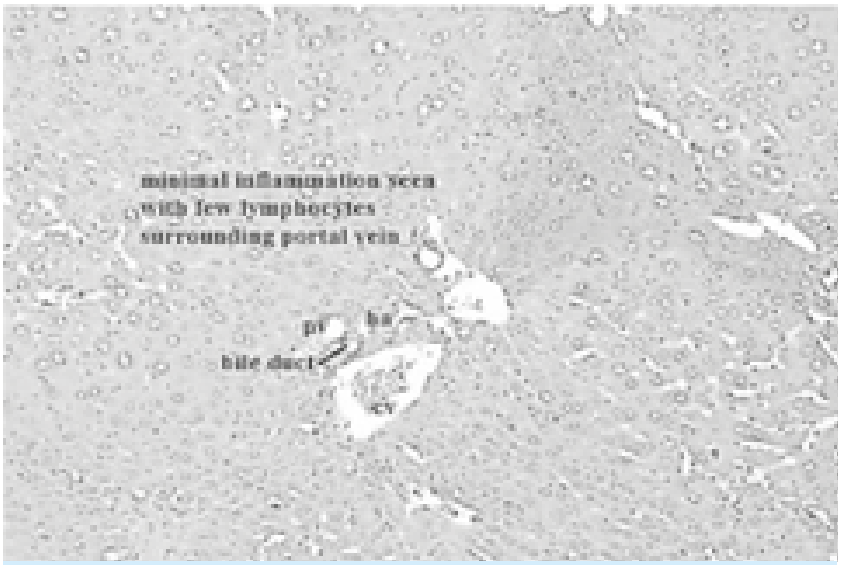

Figure-6. Group 4-dexamethasone post-treatment reduced hepatic inflammation produced by LPS.

PV -portal vein, CV central venule. Ha-hepatic arteriole. matory network. Despite tremendous research on basic and clinical levels, it still represents a challenge that we face in this era. Elderly population is more susceptible in our part of world due to high prevalence of gram negative bacterial genitourinary infection in this age group. Reevaluation of current treatment guidelines with discovery of new therapeutics adjuncts is the need of time in order to reduced sepsis associated mortalities.

Chemical shock model was reproduced in our study through intraperitoneal administration of LPS/endotoxin. Nemzek and colleagues ${ }^{18}$ have shown this model to be easily reproducible, and sterile. Mice of Group 2 become sluggish, weak and immobile with decreased intake of food and water. Shivering was also visible in these animals. Indicators of hepatic function were distorted in these animals. Serum ALT and AST were convincingly raised as compared to levels of Group 1 (Control Group) at 17 hours. Light microscopic examination of liver slides disclosed moderate to marked inflammatory changes, again a statistically compelling difference $(p \leq 0.01)$ from Group 1. Similar findings were also reported by many other researchers. Lowes and colleagues, Wei and associates in 2011, Rishi et al, all documented raised serum ALT and AST levels with hepatic architectural distortion in response to LPS administration. ${ }^{15,19,20}$

Despite questionable role, research outcomes however exhibits beneficial results of corticosteroids in sepsis induced hepatotoxicity. Dexa- 
methasone was administered at a physiologically applicable dose of $3 \mathrm{mg} / \mathrm{kg}$ (21) in animals of Group 3 and Group 4 to access its preventive and therapeutic role respectively in LPS induced hepatotoxicity. Serum analysis of animals of Group 3 (dexamethasone pre-treatment group) and Group 4 (dexamethasone post-treatment group) manifested that ALT and AST levels at 0 hours were not that different from levels at 17 hours $(p \geq$ $0.05)$, however the levels of both aminotransferases at 17 hours were eloquently different when compared with Group 2's (LPS group) terminal sampling levels. Also the architectural distortion produced by LPS in Group 2 was abated significantly $(p \leq 0.01)$ by dexamethasone in Group 3 and Group 4. In accordance to our findings were the results of study carried out by Ayact and associates in 2014 . They clearly proved that low dose dexamethasone administered 2 hours after LPS, improved survival with reduction of liver injury in mice. ${ }^{11}$ Coherent with our opinion, Wang et al (2013) demonstrated that dexamethasone (given 1 hour before LPS) abolished LPS produced liver injury as proved by restoration of serum ALT and hepatic inflammation. ${ }^{21} \mathrm{Li}$ et al determined in their study that dexamethasone was successful in reducing LPS escalated serum ALT and AST levels. ${ }^{22}$ Again these results are in concordant to our findings. Wei with his associates in 2011 disclosed that dexamethasone co-treatment with LPS injection corrected liver functions and histopathological alterations. ${ }^{15}$ Dexamethasone also succeeded in reducing LPS induced lung injury in rat, when given 30 minutes before and after LPS. $^{23}$

As a result of these findings, we are certain that dexamethasone holds both preventive and therapeutic adequacy in LPS induced hepatotoxicity through attenuation of inflammation.

We appreciate our study limitations. Therapies proven beneficial in LPS models not always turn out in same manner when tested in humans. But still animal models are only tools to access the role of new therapies that can own power and adequacy for medical world application. Future work can be done to ascertain our experimental agent efficacy in surgical and polymicrobial model of sepsis.

Copyright (C) 18 Aug, 2015.

\section{REFERNCES}

1. Angus DC, Linde-Zwirble WT, Lidicker J, Clermont G, Carcillo J, \& Pinsky MR. Epidemiology of severe sepsis in the United States: analysis of incidence, outcome, and associated costs of care. Crit Care Med. 2001; 297: 1303-1310.

2. Marshall JC, Vincent JL, Guyatt G, et al. Outcome measures for clinical research in sepsis: a report of the 2nd Cambridge Colloquium of the International Sepsis Forum. Crit Care Med 2005; 33: 1708-6

3. Yalaz M, Çetin H, Akisu M, Aydemir S, Tunger A, \& Kultursay N.. Neonatal nosocomial sepsis in a level-II NICU: evaluation of the causative agents and antimicrobial susceptibilities. Turkish J Pediatr. 2006; 48(1):13.

4. Su GL. Lipopolysaccharides in liver injury: molecular mechanisms of Kupffer cell activation. Am J Physiol-Gastr L. 2002; 283(2):G256-G265.

5. Jean-Baptiste E. Cellular mechanisms in sepsis. J Intensive Care Med. 2007; 22:63-72.

6. Arafah BM. Hypothalamic pituitary adrenal function during critical illness: limitations of current assessment methods. J Clin Endocr Metab.2006; 91:37253745 .

7. Stahn $C$ \& Buttgereit $F$ Genomic and nongenomic effects of glucocorticoids. Nat Clin Pract Rheum. 2008; 4(10):525-533.

8. Löwenberg M, Tuynman J, Bilderbeek J, Gaber T, Buttgereit F, van Deventer S.Peppelenbosch M \& \& Hommes D. Rapid immunosuppressive effects of glucocorticoids mediated through Lck and Fyn. Blood. 2005; 106(5): 1703-1710.

9. Wei SD, Li JZ, Liu ZJ, Chen Q, Chen Y, Chen M, \& Gong JP. Dexamethasone attenuates lipopolysaccharide $\square$ induced liver injury by down regulating glucocorticoid $\square$ induced tumor necrosis factor receptor ligand in Kupffer cells. Hepatol Res. 2011; 41(10): 989-999.

10. Wang ZH, Liang YB, Tang H, Chen ZB, Li ZY, Hu XC, \& Ma ZF. Dexamethasone down-regulates the expression of microRNA-155 in the livers of septic mice. PloS one. 2013; 8: e80547.

11. Aytac HO, Iskit AB, \& Sayek I. Dexamethasone effects on vascular flow and organ injury in septic mice. $J$ Surg Res. 2014; 188:496-502. 
12. Mansart A, Bollaert P E, Levy B, Nicolas MB, \& Mallié JP. Comparative effects of dexamethasone and L-canavanine in experimental septic shock. Eur J Pharmacol. 2003; 475:61-67.

13. Sprung CL, Annane D, Keh D, Moreno R, Singer M, Freivogel K, Weiss YG, Benbenishty J, Kalenka A, Forst $\mathrm{H}$, Laterre PF, Reinhart K, Cuthbertson $\mathrm{BH}$, Payen D, Briegel J. Hydrocortisone therapy for patients with septic shock. N Engl J Med. 2008;358: 111-124.

14. Patel GP, \& Balk RA. Systemic steroids in severe sepsis and septic shock. Am J Resp Crit Care. 2012;185:133-139.

15. Wang W, Zolty E, Falk S, Basava V, Reznikov L, \& Schrier R. Pentoxifylline protects against endotoxin-induced acute renal failure in mice. Am J Physiol-Renal. . 2006;291(5): F1090-F1095.

16. Brunt EM. Grading and staging the histopathological lesions of chronic hepatitis: the Knodell histology activity index and beyond. Hepatology. . 2000;31:241246.

17. Schmöcker $\mathrm{C}$, Weylandt $\mathrm{KH}$, Kahlke L, Wang J, Lobeck $H$, Tiegs $G$, \& Kang JX.. Omega $\square 3$ fatty acids alleviate chemically induced acute hepatitis by suppression of cytokines. Hepatology. 2007; 45: 864-869.

18. Nemzek JA, Hugunin KM, \& Opp MR. Modeling sepsis in the laboratory: merging sound science with animal well-being. Comparative Med. 2008;58: 120.

19. Lowes DA, Webster NR, Murphy MP, \& Galley HF. Antioxidants that protect mitochondria reduce interleukin-6 and oxidative stress, improve mitochondrial function, and reduce biochemical markers of organ dysfunction in a rat model of acute sepsis. Brit J Anaesth. 2013; 110(3): 472-480.

20. Rishi P, Bharrhan S, Bhalla MPS, Koul A, \& Chopra K. Inhibition of endotoxin-induced hepatotoxicity by melatonin in rats. Int J Biomed Sci. . 2008;4(2): 103.

21. Wang $X$, Nelin LD, Kuhlman JR, Meng X, Welty SE, \& Liu Y. The role of MAP kinase phosphatase-1 in the protective mechanism of dexamethasone against endotoxemia. Life Sci. 2008;83(19): 671-680.

22. Li YX, Wang YZ, Wang JL, Xie JM, Kang HB, \& Liu YP.. The Therapeutic Effect of Dexamethasone on Liver Injury Rat induced By Lps/D-Galn. Journal of Inner Mongolia Agricultural University (Natural Science Edition). 2012; 3: 029.

23. Araz O, Demirci E, Ucar EY, Calik M, Pulur D, Karaman A, Yayla M, Altun E, Halici Z, \& Akgun M. Comparison of reducing effect on lung injury of dexamethasone and bosentan in acute lung injury: an experimental study. Multidscip Respi M.2013;8: 74.

\section{PREVIOUS RELATED STUDY}

Ghulam Abbas Khan Niazi, Abdul Rehman Arshad, Manzar Zakaria, Waqar Ahmed, Irfan Najam Sheen. HEPATOTOXICITY OF ATT (Original) Prof Med Jour 17(3) 444-448 Jul, Aug, Sep 2010.

Muhammad Aslam Channa, Muhammad Zahoor Janjua, Muhammad Baqir Soomro, Sibghatullah Sangi. PROTECTIVE ROLE OF ANTI-OXIDANT AGAINST HEPATOTOXICITY BY CIPROFLOXACIN IN WISTAR ALBINO RATS (Original) Prof Med Jour 10(3) 196 - 200 Jul, Aug, Sep, 2003.

\section{AUTHORSHIP AND CONTRIBUTION DECLARATION}

\begin{tabular}{c|l|l|l|} 
Sr. \# & \multicolumn{1}{|c|}{ Author-s Full Name } & \multicolumn{1}{|c|}{ Contribution to the paper } & Author=s Signature \\
1 & Dr. Ammara Khan & Main Author \\
2 & Prof. Baig. Akbar Waheed & Co-Author \\
3 & Dr. Zahid Azam Chaudry & Co-Author
\end{tabular}

